\title{
The Heavens in July, 1918
}

\section{The New Star Which Has Flamed Forth in the Eastern Skies By Prof. Henry Norris Russell, Ph. D.}

$\mathrm{F}^{\mathrm{EW}}$ reports of the observations of the recent solar the appeared in astronomical circles. The weather appears, in general, to have been much less favorable than it was for the last eclipse visible in this country, that of 1900 . At Denver it was wholly cloudy; the Naval Observatory party in Oregon secured observations through the clouds; and others appear to have been similarly troubled. The party from Harvard actually had a race with the clouds in a fast automobile, and incidentally, they won this race. Detailed reports will doubtless appear in a few weeks more.

\section{Nova Aquilae}

Meanwhile, the day of the eclipse, by a singular coincidence, was signalized by an even more unusual phemomenon - the appearance of a new star, brighter than any which had been seen for three centuries. So conspicuous an object naturally attracted attention in many quarters, and its discovery was announced independently by a dozen or more observers in widely scattered places. So far as the evidence now in hand goes, it appears to have been seen first in Germany, doubtless because it rose for observers in that part of the world an hour or so earlier than in western Europe, and six hours earlier than in our eastern states. It may that some observer in Russia, India, or the Far East will prove to have detected the Nova still earlier.

On the night of June 8th, after the eclipse, the star was of magnitude 0.5-about as bright as Procyon, and nearly equal to Vega. On the ninth it had increased fully five-fold, and was of magnitude 1.4, almost as bright as Sirius, and far brighter than any other star visible in our latitude. Since then it has been gradually fading, and by the 20th it was of the second magnitudestill a conspicuous object, but no longer so bright as to attract the attention of anyone at a glance.

It is admirably placed for observation, being in the constellation Aquila, almost on the celestial equator, and about 15 degrees south and west. of Altair. It may readily be found with the aid of our star map, about half way between the stars Delta and Lambda Aquilae, and a little west of the line joining them.

To judge by the analogy of previous novae, it will probably remain visible to the naked eye for several weeks-perhaps even months-gradually diminishing in brightness. Its waning light will be of great interest to watch, and can be followed without instrumental aid of any sort.

The previous history of this star appears fortunately to be unusually well recorded in the great Harvard Library of photographs. It was photographed as a star of the eleventh magnitude on several hundred plates taken between 1888 and the present time, and showed small fluctuations in brightness from time to time, which are being carefully investigated. On June $3 \mathrm{~d}$ of the present year it was still of the normal brightness. The next three days were cloudy at Harvard. A photograph taken on the 6th showed this star of the sixth magnitude, one hundred times its previous brightness. The next night it was about two hundred times brighter yet and was one of the most conspicuous objects in the sky; and a day later it was near maximum, a hundred thousand times brighter than the week before. During that one day it gave out more light than it had done in the 250 years previous to the outburst (if one may take the last thirty of these as a fair sample).

Observations of every sort have, of course, been made in great abundance upon this remarkable object; but all that has been published up to date of writing relates to the first day or two of its visibility. At this time it showed a spectrum of the "first type" resembling that of Sirius-with narrow dark lines of hydrogen. By the present time it has doubtless changed to the typical nova spectrum, with broad hoped that sufficiently numerous observations have been secured in different longitions have been secured in different longi-
tudes to make it possible to follow the tudes to make it possible to follow the
rapid changes in the spectrum near the rapid changes in the spectrum near the The changes which occur during decreasing light are well known. All novæ, when just past their maxima, show the characteristic spectrum just described, which is very similar in all cases and like that of nothing else in the heavens. As the stars fade in brightness the character-

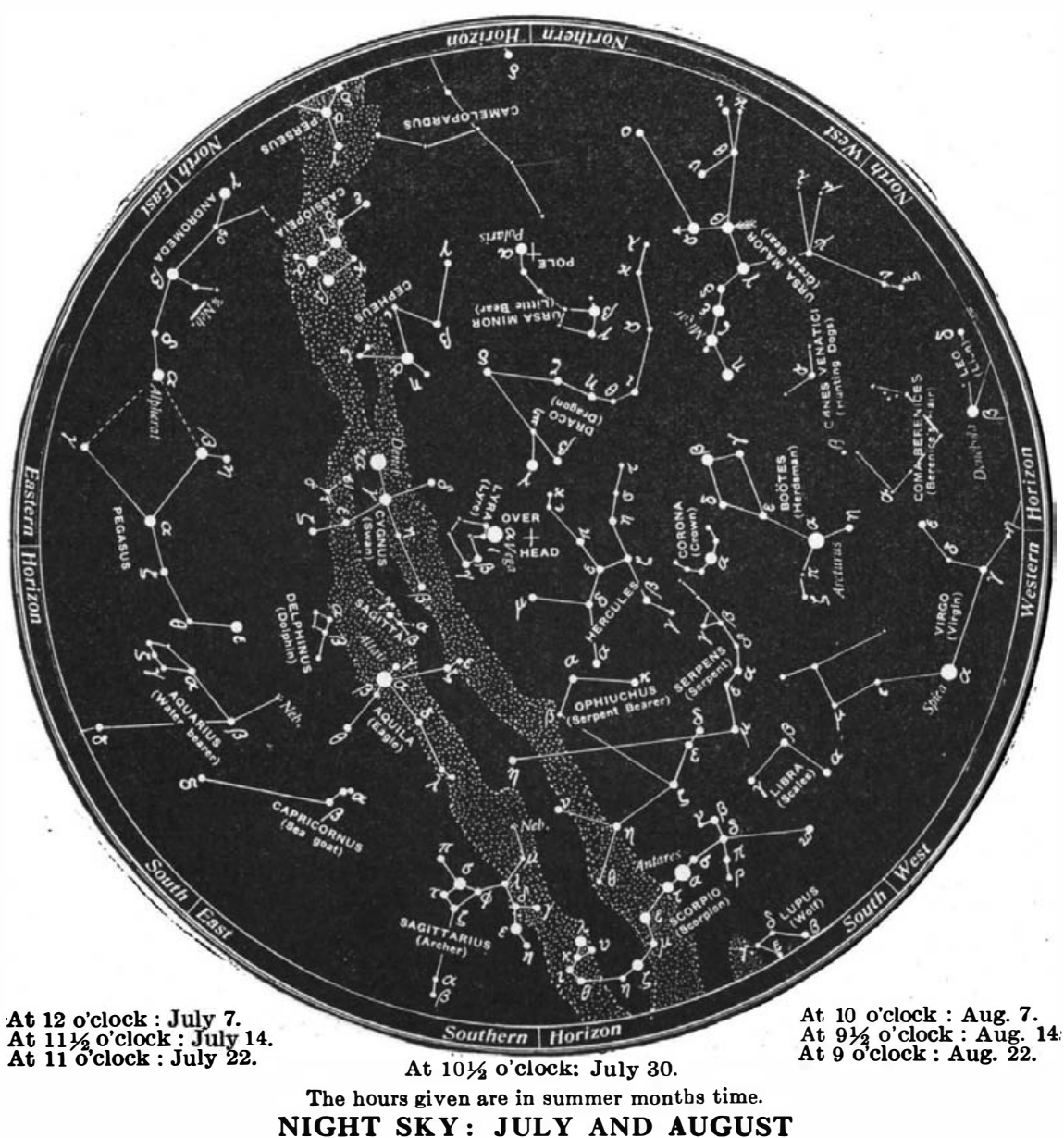
NIGHT SKY : JULY AND AUGUST tance being at least 150 light years, and probably considerably more; and it does not seem likely that the present object is an exception to this rule. But if it is no more distant than 100 light years, it must at maximum have been at least five thousand times as bright as the sun-and this is probably an underestimate. How can such a terrific outburst of light and heat be developed within two or three days? And, when once it has taken place, why does the star which has thus, become so brilliant fade away again, usually to a hundredth part of its greatest light after a few weeks, and almost to its original low estate after a few years?

No theory has yet been developed which will fully account for all the facts; but two things at least seem to be practically certain. First, the outburst, whatever it is, is a superficial phenomenon. It must be only the surface of the star, and not the whole huge mass of its interior, which becomes heated to a degree that would believing this is the rapidity with which the light fades. If the whole mass of the star were heated as hot as the surface, we might expect it to keep on shining brightly for years-perhaps for centuries.

Secondly, these outbursts are by no means unusual occurrences. It is only 17 years since the appearance of a temporary star in Perseus, almost as bright as this one, and in the interval have been seen at least four others which would have been visible to the naked eye if they had been discovered before they reached their maximum brightness. -Add to this the further ones, visible only with the telescopes, and it appears that such outbursts must occur somewhere among the stars every year or two.

These two conclusions dispose entirely of two theories which at first might attract attention. The first is that of a collision between two stars. The stars are such exceedingly small bodies, in comparison with the distances between them, that it can easily be shown that, even if we include all the hundreds of millions of known stars, the average intervals between collisions must be many millions of years, while temporary stars appear every year or two. Moreover, a collision would heat up the whole mass of the colliding bodies, unless it happened to be a merely grazing impact; and even this would produce a mass of furiously incandescent matter so huge that it would shine for a long time.

The other plausible hypothesis, which fares little better at the hands of the facts, is that of an internal explosion, due for instance, to the sudden liberation of radio-active energy within a star. We cannot, of course, maké any estimate of how often such a catastrophe might occur among the stars, if indeed it be possible at all. But if it did happen, it would again involve the whole mass of the star and presumably produce long-lived consequences. Fortunately, there is a theory which escapes these objections, and which fits most of the observed facts posed by Seeliger, that the cause of the disturbance is a collision between a star and a nebula. In this case, the nebular material would be attracted by the star, and rain down into the star's atmosphere with a very high velocity, producing an enormous meteoric shower all over its sura few hours or days to a very high temperature. As soon as the bombardment ceased, the surface would begin to cool; and years would see it pretty well cooled off This accounts for the temporary character of the phenomenon. With respect to the frequency of such occurrences it is only necessary to remark that nebulae are big a bullet hitting a cloud; for two stars to collide in flight would be like two bullets in flight hitting one another.

The theory of collision with a nebula therefore, accounts for the main features of the affair. But many spectroscopic details remain unexplained. Observations during the rapid rise in brightness may present the clue to the maze; and this time there is good reason to hope that many have been secured.

One word more: we must be careful not to think of the great stellar catastrophe as having actually occurred on the day of the eclipse. The light by which we saw it had been on its way certainly for decades, probably for centuries; and it is more (Concluded on page 24) account for the amazing brilliancy. The reason for excellently. This is the idea, first proface, which would heat the outer layers in the heat layer being only skin deep, a few targets. For a star to enter a nebula is like 


\section{WHYTING-ADAMS BRUSHES A}

S ALL GRADES

FOR'THEGREAT CARRIERS OF THE WORLD The requirements of Railroads and
Steamships demand best quality, long

Whiting-AdamsBrushes

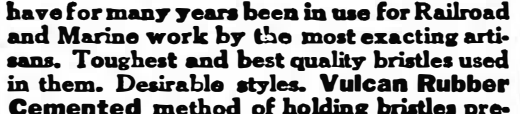

John L. Whiting-J. J. Adams Co. BOSTON, U.S. A.

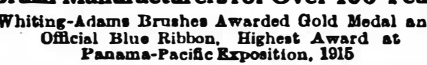

\section{More Value}

from Your Machine

Your machine has a value that can only be realized by checking up its production, keeping it up to top-notch by watching its record on a

\section{Seeder COUNTER}

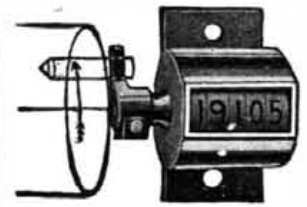

The Revolution Counter
at left registers one for a revolution of a shaft, recording an operation chinery and experiment

Practically any machine can be properly equipped from the counters shown

THE VEEDER MFG. CO.

18 Sargeant St., Hartford, Conn

\section{VENUS}

7 HE only way to get a pencil as good as a VENUS is to buy a nother VENUS Pencil!

17 black degrees $6 B$ softest to 9 and hard and $m$ dium copying - all perfect!
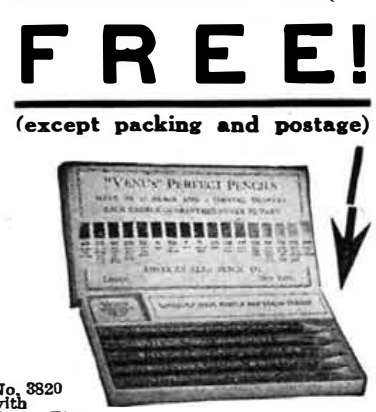

Send $6 c$ in stamps to cover actual
cost of packing and postage ant cost of packing and postage and
we'll send FIVE trial length VENUS

American Lead Pencil Co. 217 Fifth Avenue, New York the readybalancing of the companion blades. wrongful, although committed in the Tmall lead washers are placed in holes in course of performance of a contract with both blades, and by transferring washers the United States. But, if on the other rom one hole to another balance is soon hand, the acts of manufacture were onl established. The washers are held in place contributions to an infringement resulting by a screw in each hole.

One of his objects in making the auxiliary the provisions of the Act of 1910 no illegal lades shorter than the leaders, explains interference with the rights of the patentee Mr. Irving, is for the purpose of obtaining arose or could arise from the mere furnishan advanced, differential.pitch with which ing to the Government of the United States to create impelling force from the inner, of the parts which were not per se infringeslow-speed circle or "dead" space; and ments, even although the use by the United results from numerous practical flying States would infringe the patents. Where tests quite justify the claim that the the manufacture by the contractor is not propeller is fully one-third more efficient an intrinsic or per se infringement, the than the usual design, and at no extra cost of power. When used as a tractor, the concentrating action of the auxiliary blade results in enveloping the fuselage for its entire length within a cylinder of air wash of somewhat less diameter than the short blades. It is also apparent that these valuable purpose, namely, that of forcing or assisting the leading blades into the undisturbed air. But $\mathrm{Mr}$. Irving is not given to theories: he merely states that he has a propeller that does the work, and that it is more or less inconsequential to the practical aviator just how it does the work. Considerable success has attended the use of Mr. Irving's marine propeller, depresent air screw. Some years ago Captain Baldwin, a well-known figure in American aviation, tested one of the Irving propellers on his "Red Devil" biplane. Crude as that propeller was, the, the results were most gratifying. Captain Baldwin was astonished with the climbing power and speed of his machine so equipped. Other aviators have also been impressed in the
same way, after a trial of the propeller which ridicules propeller theories.
.

The Use of Patented Inventions b the United States Government (Concluded from page 14)

press or implied, for compensation for the likely than not that this event, which beuse of the patent rights. In such a case $\begin{aligned} & \text { came visible on earth during the present } \\ & \text { great war, really took place long before }\end{aligned}$ it was necessary to show that the officer the great Napoleonic wars of a century ago. of the United States had knowledge of the patent right and its validity, and that he
proceeded in the use of the patent right proceeded in the use of the patent right
with the express or implied consent of the owner of the patent. But where the officer of the United States infringed patent rights under circumstances not justifying the implication of a contract the only redress the owner of the patent had was against the officer. The statute of 1910 provided for the recovery by the owner of a patent in the Court of Claims of reasonable compensation for all patents used by the United States. This statute States Supreme Court in two cases.

States Supreme Court in two cases.
In the case of William Cramp \& Sons, In the case of William Cramp \& Sons,
et al. vs. International Curtis Marine et al. vs. International Curtis Marine
Turbine Co., it was held that the statute merely provided for the recovery by the owner of a patent of compensation for the use of the patent by the United States and that a contractor with the United States is not under the statute vested with the power to take the property of others upon the assumption that as a result of the contract with the United States he enjoys the right to exercise public and governmental powers possessed by the United States. The contract does not the United States qualified to represent it and to entail obligations under it, which under the Act of 1910 providing for the under the Act of 1910 providing for the
compensation of patentees can only rest upon official action and the discharge of official duty. In such a case the contractor is liable like any other individual.

In the decision in Marconi Wireless Telegraph Co. vs. Simon, a distinction was made between cases where the manufacture by the contractor was an intrinsic or per se infringement and cases where
the goods of the contractor only constituted contribution to the infringement. It was held in this second case that if the manufacture was in and of itself an infringement, the manufacture was not
protected by the supposition of a license protected by the supposition of a license
resulting from the Act of 1910 , and that resulting from the Act of 1910 , and that
the manufacturer's acts were nevertheless June 22, 1918.
Strategic Moves of the War (Concluded from page 8)

cuntry. in the first three days of the battle in rossing at three places where the roads ridges had been destroyed. After reaching the west banks, however, heavy floods wept away most of the bridges and marooned upon the western banks. The Piave River from the hill of Montello to the sea, thus evacuating all the river territory gained in their great drive. This as to be expected in view of the dangerous ank. For the present at least, it would he Austrians can be expected, as their on some time to recuperat

The Heavens in July, 1918

he Heavens

Our map shows the principal constelations, and makes a long description unnecessary. Scorpio and Sagittarius are the East, with Cye South, Pegasus low in nd Lyra overhead. Cassiopeia is in the Northeast, Draco and Ursa Minor in the Hercules is high in the West, with Bootes below and Virgo still lower, while Ophiuchus and Serpens are well up in the outhwest.

Mercury is a morning star all through uly-too near the sun to be seen at first, month, when he sets at 9.20 P. M. Summer
. Sume Time. Venus is a morning star in Taurus 3.30 A. M. in the middle of the n evening star, setting about midnight. upiter is a morning star in Gemini, not $r$ from Venus. On the morning of the 6 th, the two planets are in conjunction, nd little more than half a degree apart. This close approach of the two brightest the planets will be worth looking at. 列 month. On the 17th he is in conjunction ess than half a degree apart when apparently closest at 1 P. M., and but little more widely separated when visible that vening. Uranus is in Aquarius, while Neptune is in Cancer. the 1 st, new at $4 \mathrm{~A}$. M. on the 8 th, in the frst quarter at $2 \mathrm{~A}$. M. on the 16 th, full t 5 P. M. on the 23d, and in her last quarter again at $9 \mathrm{~A}$. M. on the 30 th. She nearest us on the 26th, and furthest the sky, she passes near Venus on the 5th, upiter on the 6th, Mercury and Neptune on the 9th, Saturn on the 10th, and Mars eaten Austrian forces have accordingly osses in both men and material must have and Gemini, and is very conspicuous, rising with Mercury, the two planets being rather

The moon is in her last quarter at $5 \mathrm{~A} . \mathrm{M}$.
LEGAL NOTICES

PATENTS

IF YOU HAVE AN INVENTION which you wish to patent you can
write fully and freely to Munn \& Co. write fully and freely to Munn \& Co. for advice in regard to the best way sketches or a model of your invention and a description of the device, explaining its operation.

All communications are strictly confidential. Our vast practice, extending over a
period of seventy years, enables us in many
cases to advise in regard to patentability without any expense to the client. Our
Hand-Book on Patents is sent free on request. This explains our methods, terms,
etc., in regard to Patents, Trade Marks,
Foreign Patents, etc. Foreign Patents,
All patents secured

MUNN \& CO.

SOLICITQRS OF PATENT

233 Broadway, Woolworth Building.

And $625 \mathrm{~F}$ Street, Washington, D. C.

Annual Subscription Rates for the Publications $\$ 4.00$ Postage prepaid in United States and po
Mexico, Cuba and Panama.

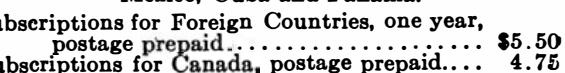
The Scientific American Publication

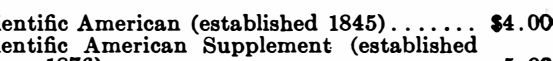
The combined subscription rates and rates to foreign
countries, including Canada, will be furnished upon application.
Remit by postal or express money order, bank

Classified Advertisements Advertising in this column is $\$ 1.00$ a line. No
less than four nor more than 12 lines accepted.
Count seven words to the line. All orders must be
accompaned by a remittence. INVENTIONS AND IDEAS WANTED SEND sketch and description to St. Louis Art Co.
447 Pierce Building, St. Louis, Mo. If we cannot use it
e can help you. Conflential. schools
Jmprove Your Vópe

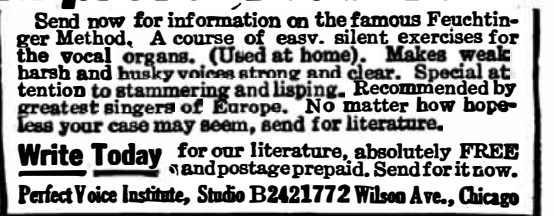

diana Terre Hate,
ROSE POLYTECHNIC INSTITUTE A Oo llege of Engineerin g. Courses in Mechanical,
Electrical, Civil, Chemical and Architectural Engineer-
lng. Extensive shops, well-equipped laboratories in all lng. Extensive exhops, well-equiped laboratories in all
departments, expenses low 35 th year. For catalog
containing full information and professional register of
alumni, address F. L. Mees, President LEARN TO BE A WATCHMAKER

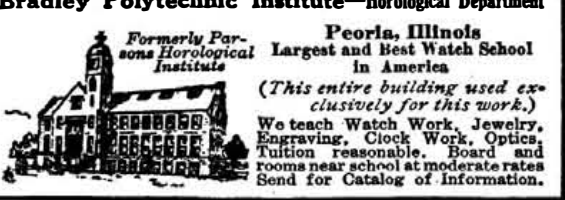

\section{Manufacturers}

Would it be of value and assistance to you to have a classified set of Uni.ted States Patents relating to your particular line of manufacture for ready reference? If so, write to our Manufacturers' Service Department for particulars.

\section{MUNN \& $\underset{\text { PATENT ATTOREYS }}{\text { CO. }}$} 626 Woolworth Building New York City 


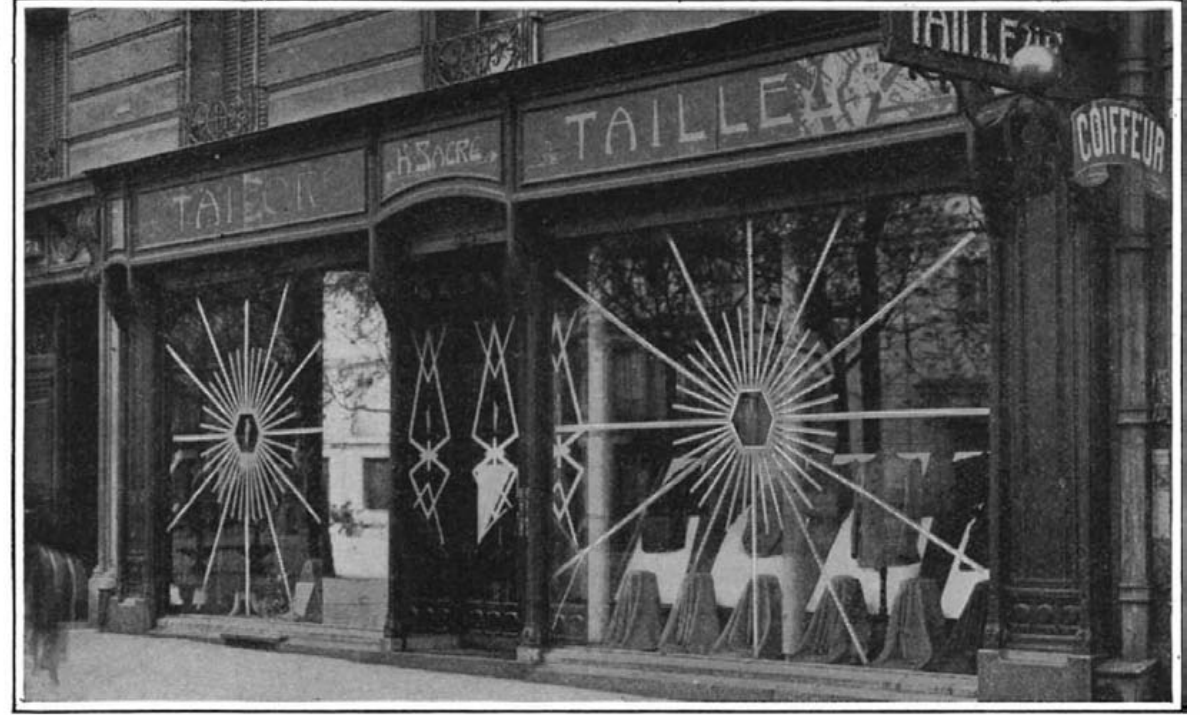

This Parisian tailor protected his shop windows by a sunburst design for his paper tapes, thus combining art with utility

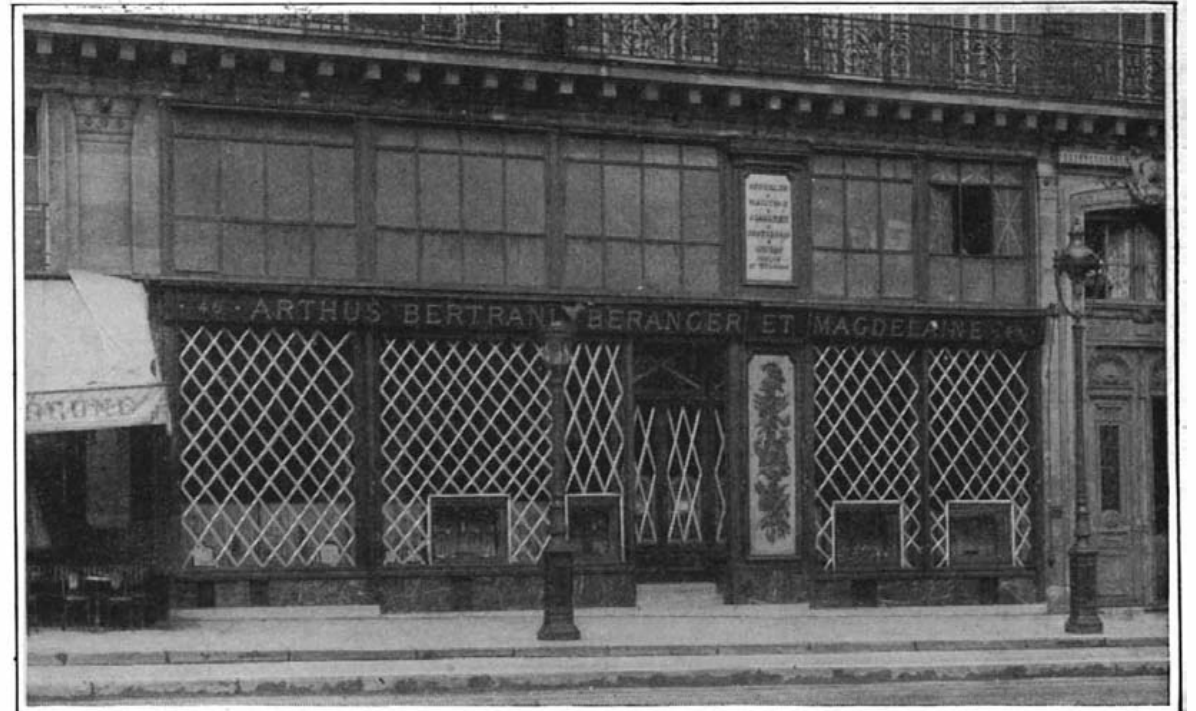

This jeweler has followed a more conventional lattice-work design, leaving small square windows in line with show cases
Paper Taped Shop Windows of Bombarded Paris

PARISIANS have that most enviable faculty of making the most out of any misfortune. All the world knows it-except the Germans; and that is why the German airmen and artillerymen keep sending missiles into Paris with the object of terrorizing and discouraging the Parisians, without realizing that they are not only failing in their task, but are stirring still greater hatred against them

So it was that when the German longrange guns began to bombard Paris, the government advised the metropolitan folk to keep their windows open wherever possible, in order to offer the least resistance to the rush of air following the explosion of German shells. In instances where windows could not be opened, particularly plate-glass store fronts, the authorities advised the use of paper tape about four inches wide, carefully and tightly glued on the inside of windows in some diagonal shape to take up the bending stresses of the glass surfaces.

The Parisians followed the instructions. They not only followed them but they went one step further: progressive shop keepers saw the decorative possibilities of the paper tapes and immediately set to work on elaborate designs tending to attract attention to their displayed wares. As a result, there is today in Paris no end to weird window designs which lend a new touch to the city's stores. In fact, the Hun gunners somewhere in the St. Gobai forest are materially boosting Parisian trade by their daily work, even though they may not be aware of this fact.

Second-Hand Store of the Battle-Line

GECOND-HAND dealers do a thriving $S$ trade in the war zone. Not only have they no trouble in securing their stocks in regions where the wreckage of war is to be found on all sides, but there is considerable demand on the part of soldiers for various second-hand articles. Then there is a big opportunity for the display of ingenuity: the second-hand dealer can do much in the way of restoring partly or wholly the pieces of wreckage which come to him, thereby increasing their sales value.

Typical of the battle-line second-hand shop is that depicted in the accompanying illustration, presumably taken at the rear of the Canadian battle-front in France. Here may be seen a Canadian out for bargains and evidently having found one in the shape of an old soft hat. It is said of these second-hand shops that they contain anything from a bird-cage to a cradle, and aside from these two articles the illustration shows a phonograph horn, bicycle frame, chair, floral frames, hotwater bag and several other equally varied objects.

How the Lewis Gun Is Stripped for Service on Aircraft

FOLLOWING the example of British $F$ and French fighting aircraft, our own battleplanes are to be equipped with Lewis guns, although recent announcements of the Ordnance Bureau make it plain that the Browning heavy gun and the Marlin aircraft gun are also to be used. But at this very moment it is perhaps safe to

state that more Lewis guns have been employed on Allied battleplanes than any other type of gun.

For air service, the Lewis gun is stripped of its characteristic cooling jacket or "hose," because the high speed of the airplanes with the consequent rush of cold air, makes a large cooling surface totally unnecessary. The spade handle is used in place of the ordinary butt stock, greatly facilitating the quick handling of the gun by the fighting aviator. Another change is to be found

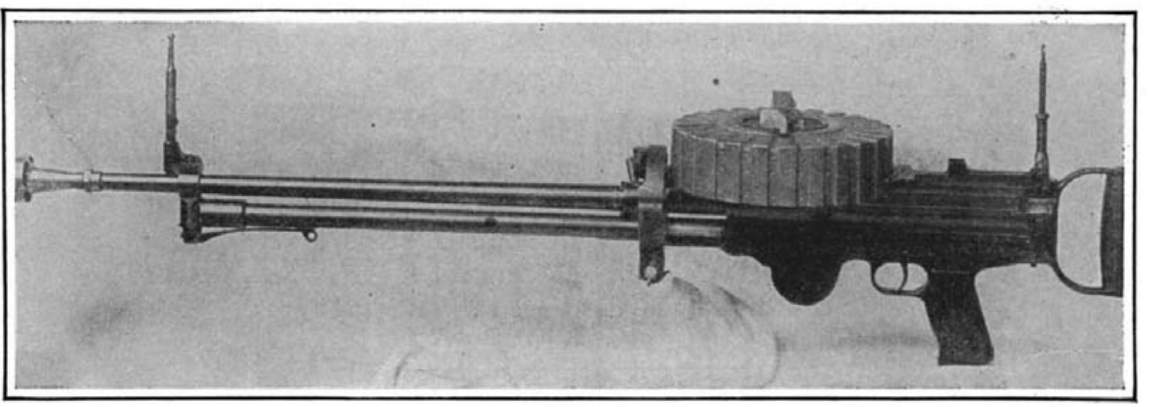

Lewis gun stripped of radiating barrel and fitted with spade handle and special sights for airplane work

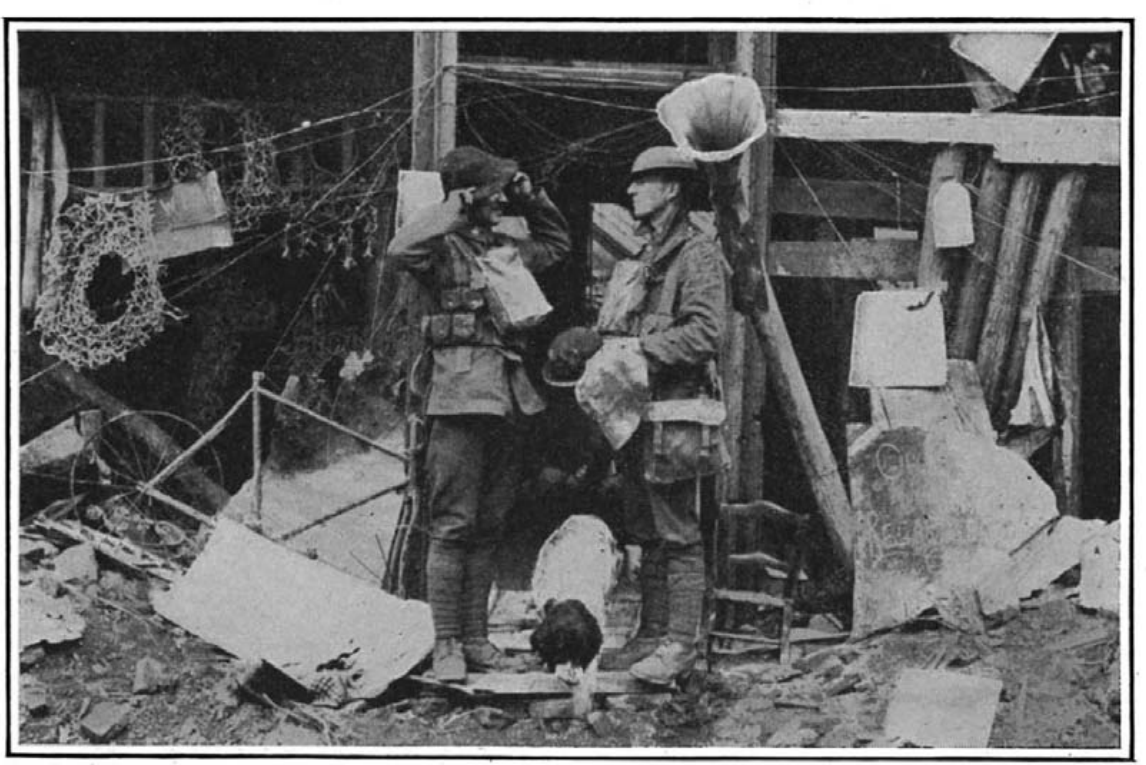

Canadian buying a hat at a second-hand store near Lens

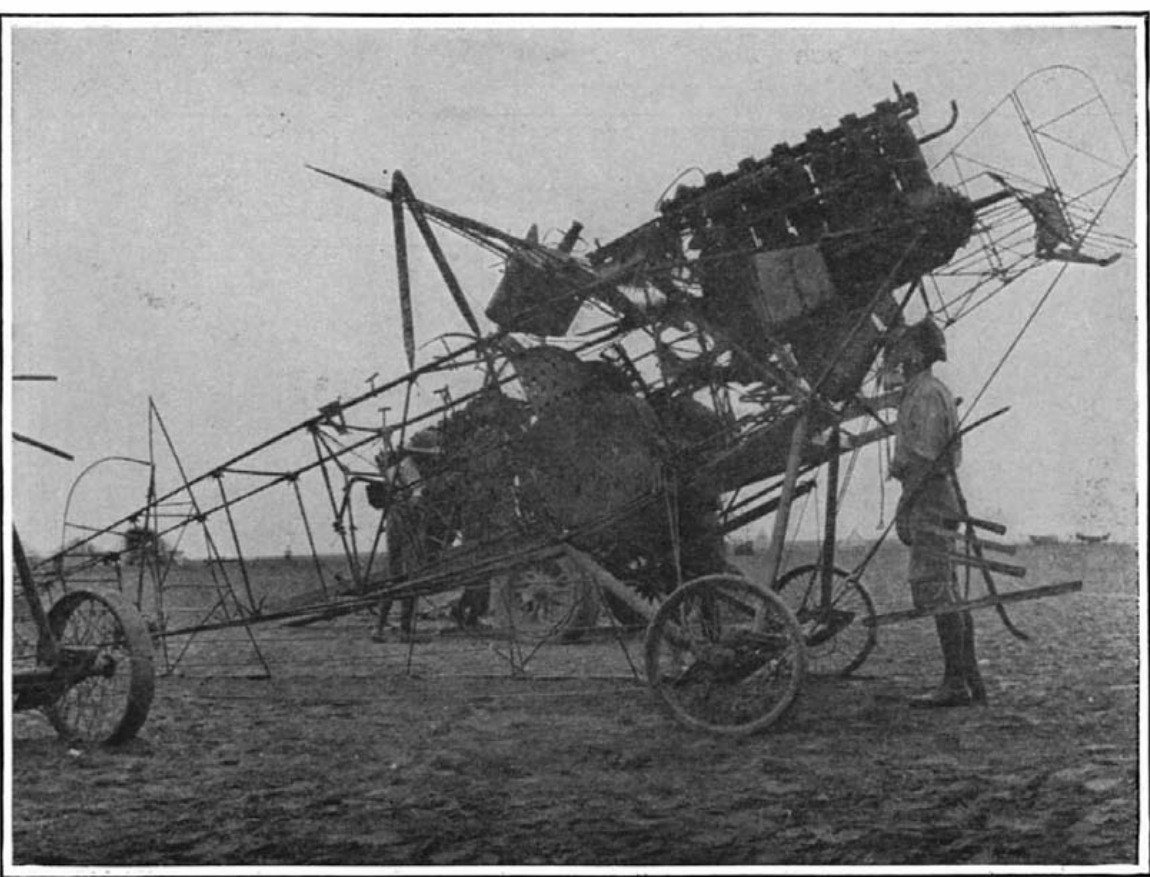

Graphic proof that Germany's aircraft industry is hard pressed: An enemy machine built of steel tubing instead of spruce in the sights, which in this case consist of a bead at the ront end and a fairly large ring at the rear-an arrangement which is sufficiently accurate under the conditions aerial warfare.

The Lewis gun is employed on French and British battleplanes as a supplement to the heavier Maxim gun, in the latest planes. The latter is generally a rigidlymounted piece firing through the propeller by means of a nchronized firing device, while the former or Lewis gun is mounted above the top plane, or on a cradle arrangement in the rear cockpit, where it can be handled by the pilot or the observer, respectively: Either arrangement applies to tractor machines. In the case of pusher planes the Lewis gun is placed on a cradle mounting in front and operated by the observer or gunner. Formerly, the Lewis gun was employed in Nieuport machines above the top plane so as to clear the sweep of the propeller, and was operated by the pilot by means of a Bowden wire control.

\section{Can Germany Keep Up Her Airplane} Production?

THERE has been something decidedly impossible about the way in which Germany has maintained her aircraft production. That is to say, despite the large percentage of men called to the colors; despite the demands of other war industries and the farms for labor, whether men or women or children; despite the complete isolation of the German Empire from the outside world, German airplanes have not been found lacking in numbers or in quality in the competition with Great Britain France, Russia, Italy and theUnited States. But presently the mystery is rapidly clearing. Germany, we are about to learn cannot do the impossible any more than any other nation. The truth is that Germany has put up a plucky fight in the air, but her vast aircraft production is now finding itself hard pressed for labor and materials. There is undeniable evidence that the Germans are running short of suitable materials, and in consequence are using inferior timber and textiles. Captured German machines exhibit a desperate effort to maintain quantity production at the cost of using poor material and hurried labor. For instance, the wing beams of the captured planes are often made of thin pieces, less than an inch in thickness, put together with glue and nails. American specifications require solid beams of the finest and toughest spruce. Wings of the German planes are covered with a fiber cloth instead of the stout linen used on Allied planes.

We are told thatour winged enemies refuse to enter into a combat calling for the usual range of trick flying, because their poorly built machines cannot stand the strairs imposed. Rather than accept combat under circumstances calling for other than straight flying, German machines are now said to turn and make off for their lines at full speed. Numerous German planes have been seen to crumple and fall from no other apparent reason than structural defects. Steel tubing, which the Germans are using in increasing quantities for their planes, is proving far inferior to spruce which is now beginning to lack in Germany. 